\title{
Odor preference learning and memory modify GluAl phosphorylation and GluAl distribution in the neonate rat olfactory bulb: Testing the AMPA receptor hypothesis in an appetitive learning model
}

\author{
Wen Cui, ${ }^{1}$ Andrea Darby-King, ${ }^{1}$ Matthew T. Grimes, ${ }^{1}$ John G. Howland, ${ }^{3,4}$ \\ Yu Tian Wang, ${ }^{5}$ John H. McLean, ${ }^{1,6}$ and Carolyn W. Harley ${ }^{2}$ \\ ${ }^{7}$ Division of BioMedical Sciences, Memorial University of Newfoundland, St. John's NL, A1B 3 V6 Canada; ' ${ }^{2}$ Department of Psychology, \\ Memorial University of Newfoundland, St. John's NL, A1B $3 X 9$ Canada; ${ }^{3}$ Neural Systems and Plasticity Research Group, Department \\ of Physiology, University of Saskatchewan, Saskatoon SK, S7N 5 A5 Canada; ${ }^{4}$ Neural Systems and Plasticity Research, Group, \\ Department of Psychology, University of Saskatchewan, Saskatoon SK, S7N 5 A5 Canada; ${ }^{5}$ Brain Research Centre and Department \\ of Medicine, Vancouver Coastal Health Science Institute, University of British Columbia, Vancouver BC, V6T 2B5 Canada
}

\begin{abstract}
An increase in synaptic AMPA receptors is hypothesized to mediate learning and memory. AMPA receptor increases have been reported in aversive learning models, although it is not clear if they are seen with memory maintenance. Here we examine AMPA receptor changes in a CAMP/PKA/CREB-dependent appetitive learning model: odor preference learning in the neonate rat. Rat pups were given a single pairing of peppermint and $2 \mathrm{mg} / \mathrm{kg}$ isoproterenol, which produces a 24- $\mathrm{h}$, but not a 48-h, peppermint preference in the 7-d-old rat pup. GluAl PKA-dependent phosphorylation peaked 10 min after the 10-min training trial and returned to baseline within $90 \mathrm{~min}$. At $24 \mathrm{~h}$, GluAl subunits did not change overall but were significantly increased in synaptoneurosomes, consistent with increased membrane insertion. Immunohistochemistry revealed a significant increase in GluAl subunits in olfactory bulb glomeruli, the targets of olfactory nerve axons. Glomerular increases were seen at 3 and $24 \mathrm{~h}$ after odor exposure in trained pups, but not in control pups. GluAl increases were not seen as early as $10 \mathrm{~min}$ after training and were no longer observed $48 \mathrm{~h}$ after training when odor preference is no longer expressed behaviorally. Thus, the pattern of increased GluAl membrane expression closely follows the memory timeline. Further, blocking GluAl insertion using an interference peptide derived from the carboxyl tail of the GluAl subunit inhibited $24 \mathrm{~h}$ odor preference memory providing causative support for our hypothesis. PKA-mediated GluAl phosphorylation and later GluAl insertion could, conjointly, provide increased AMPA function to support both shortterm and long-term appetitive memory.
\end{abstract}

[Supplemental material is available for this article.]

\begin{abstract}
Odor preference learning in the neonate rat pup offers a unique mammalian classical conditioning model because the neuromodulator norepinephrine (NE) serves as the unconditioned stimulus (US), whereas the conditioned stimulus (CS) is a novel odor (Sullivan et al. 1989, 1991, 1992, 2000). In invertebrates the NE analog, octopamine (Scheiner et al. 2006), is known to act as a US for appetitive classical conditioning (Hammer 1993; Hammer and Menzel 1998; Schwaerzel et al. 2003; Unoki et al. 2005), but in mammals, neonate odor preference learning is, at present, the only model in which a biogenic amine paired with a sensory input produces associative appetitive learning. Further, the olfactory bulb, where the functional/structural changes necessary and sufficient for odor preference learning and memory occur (Sullivan et al. 1991, 2000), is a relatively simple cortical structure in which a single neuronal type (mitral/ tufted cells) receives odor input in a glomerular structure and relays odor output through the lateral olfactory tract. A novel
\end{abstract}

${ }^{6}$ Corresponding author.

E-mail mclean@mun.ca; fax (709) 737-7010.

Article is online at http://www.learnmem.org/cgi/doi/10.1101/lm.1987711. odor paired once with moderate activation of $\beta$-adrenoceptors in the olfactory bulb produces short-term memories and 24-h memory, but not 48-h memory (McLean et al. 2005). This learning depends on optimal activation of a cAMP-dependent pathway paired with the odor input (Yuan et al. 2003; Cui et al. 2007).

A long-standing view of learning and memory suggests its major substrate is an increase in glutamatergic AMPA receptor function (Lynch and Baudry 1984). Initially, modified glutamatergic AMPA receptor function associated with receptor phosphorylation could rapidly mediate a functional increase, followed by an increase in synaptic AMPA receptor insertion, and, subsequently, structural synaptic enlargement. Methodological progress has made it possible to find in vivo evidence for an AMPA receptor increase in association with mammalian fear conditioning (Rumpel et al. 2005; Whitlock et al. 2006; Yeh et al. 2006; Matsuo et al. 2008) and a dependence of some forms of learning on cAMP-dependent protein kinase A (PKA)-mediated phosphorylation of AMPA receptors (Lee et al. 2003). Peak AMPA receptor-gated currents are increased by PKA phosphorylation of serine 845 on the AMPA receptor GluA1 subunit (Banke et al. 2000). An increase in synaptic AMPA receptors is proposed 
to occur through a two-stage process in which increased extrasynaptic AMPA receptor insertion is triggered by PKA phosphorylation of the GluA1 subunit, followed by activity-dependent synaptic targeting of GluA1-containing AMPA receptors by receptor lateral movements mediated by other mechanisms (Sun et al. 2005; Oh et al. 2006). The role of $\beta$-adrenoceptor activation leading to PKA-dependent serine 845 phosphorylation has been highlighted as a mediator of the emotional enhancement of memory via increased extrasynaptic delivery of GluA1 containing AMPA receptors acting as a prime for the enhancement of long-term potentiation (Hu et al. 2007).

As short- and long-term memory, as well as loss of memory, can be probed in cAMP-dependent one-trial neonate odor preference learning, this model permits direct testing of the hypothesis that PKA-mediated GluA1 receptor phosphorylation on serine 845 , and/or changes in the distribution or levels of the GluA1containing AMPA receptor, are initiated with appetitive learning and support memory. The present results are consistent with the AMPA receptor hypothesis and provide new insights into AMPA receptor trafficking in mammalian learning and memory.

\section{Results}

To explore the effect of odor preference training on p-GluA1 and GluA1 expression in the olfactory bulb, the data of trained pups were compared to the data from naive littermates (Mean pGluA1/ GluA1 optical density ratio \pm SEM $=0.735 \pm 0.0935$ ). A one-way repeated ANOVA showed that p-GluA1 expression increased significantly from the end of the 10-min conditioning session up to $1 \mathrm{~h}$ after conditioning $\left(F_{(10,30)}=6.00, P<0.001\right)$ (Fig. $\left.1 \mathrm{~A}\right)$, including $0 \mathrm{~min}$ (mean $\pm \mathrm{SEM}=1.048 \pm 0.1001, P<0.01), 5 \mathrm{~min}$ $($ mean $\pm \mathrm{SEM}=1.01 \pm 0.1453, P<0.05), 10$ min $($ mean $\pm \mathrm{SEM}=$ $1.31 \pm 0.1947, \quad P<0.0001), \quad 20 \mathrm{~min} \quad($ mean $\pm \mathrm{SEM}=1.15 \pm$ $0.1759, P<0.01), 30$ min (mean $\pm S E M=1.198 \pm 0.2406, P<$ $0.01)$, and $1 \mathrm{~h}$ (mean $\pm \mathrm{SEM}=1.118 \pm 0.1271, P<0.01)$. During this period, p-GluA1 showed the highest level at $10 \mathrm{~min}$ after training, the same time that PCREB expression was maximally increased (Yuan et al. 2000) in an earlier study. After $1 \mathrm{~h}$, p-GluA1 subsided to naive levels and did not show any difference from the naive group up to and including $24 \mathrm{~h}$ after, specifically $1.5 \mathrm{~h} \quad($ mean $\pm \mathrm{SEM}=0.9125 \pm 0.09178), \quad 2 \mathrm{~h} \quad($ mean $\pm \mathrm{SEM}=$ $0.8875 \pm 0.066), \quad 3 \mathrm{~h} \quad($ mean $\pm \mathrm{SEM}=0.7275 \pm 0.07609)$, and $24 \mathrm{~h}$ (mean $\pm \mathrm{SEM}=1.005 \pm 0.04992)$ means did not differ from naive controls.

GluA1 expression was measured and analyzed in the same way as that of p-GluA1 expression. No difference in its levels from those of naive pups were seen for the trained, odor plus $2 \mathrm{mg} / \mathrm{kg}$ isoproterenol, group at any time point during the one day time course measurements (Fig. 1B).

The pattern of phosphorylation of the GluA1 subunit is congruent with the hypothesis that the pairing of odor and $\beta$-adrenoceptor activation initiates learning through activation of the cAMP/PKA/CREB cascade. Here maximal phosphorylation of the GluA1 PKA site occurs at 10 min post-training. This parallels the CREB phosphorylation pattern reported earlier with odor preference training in which CREB phosphorylation was also maximal at $10 \mathrm{~min}$ post-training. A similar peak in the phosphorylation of the NMDA receptor PKA site at 10 min has been observed in our laboratory after odor preference training. The failure to see sustained GluA1 phosphorylation at this site suggests that the short-term memory seen at $3 \mathrm{~h}$ following training is not supported by covalent modification of the AMPA receptor, at least not by sustained modification of the PKA-targeted phosphorylation site.

While this first set of experiments demonstrates increased phosphorylation of the GluA1 subunit at 10 min following odor preference training, they do not demonstrate that such phosphorylation is selectively related to training. For example, isoproterenol itself or novel odor alone might induce increases in phosphorylation. To ask whether the enhanced phosphorylation
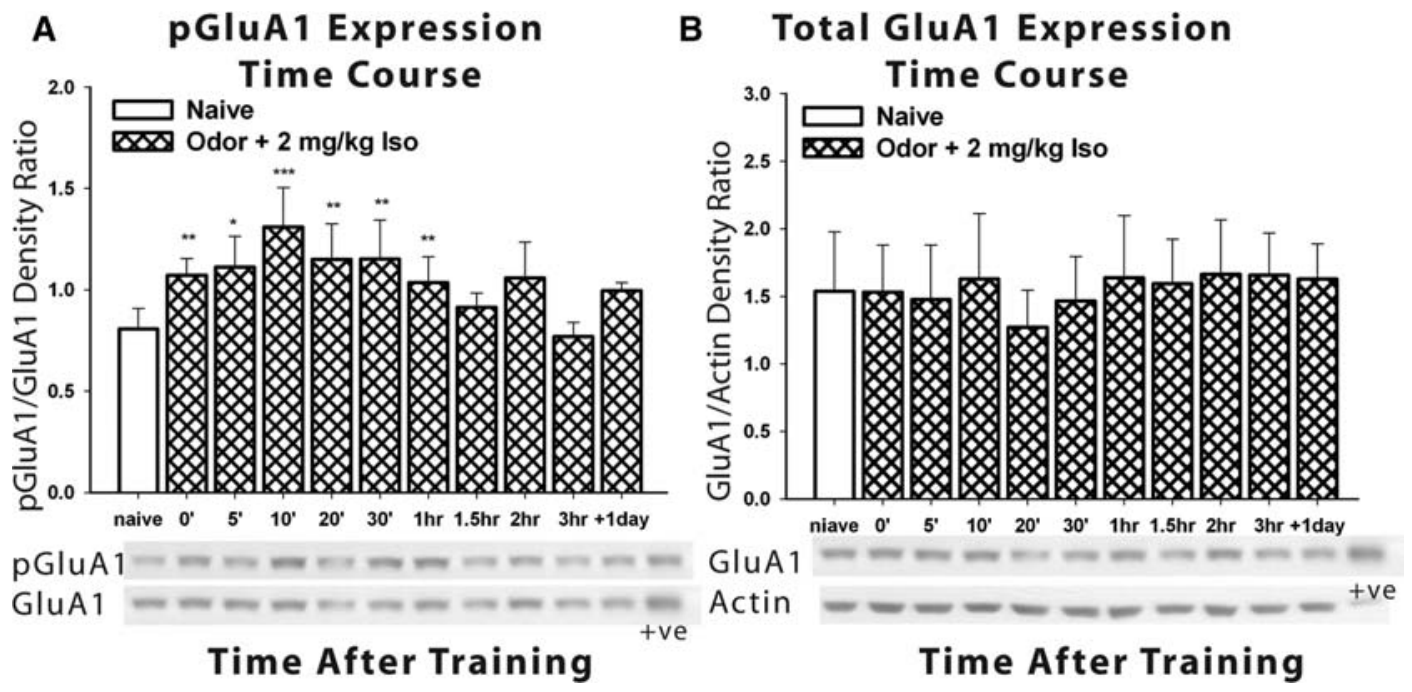

Figure 1. (A) Phospho-GluA1 expression observed in Western blots representative Western pGluA1 and GluA1 blots are shown at the time points quantitated immediately below. The relative $\mathrm{p}$-GluA1/GluA1 expression in pups trained by pairing of odor plus $2 \mathrm{mg} / \mathrm{kg}$ isoproterenol increased significantly from the immediate end of conditioning up to $1 \mathrm{~h}$ after, compared with that of naive pups, including 0 min $(P<0.01), 5$ min $(P<0.05), 10$ min $(P<$ 0.001), $20 \mathrm{~min}(P<0.01), 30 \mathrm{~min}(P<0.01)$, and $1 \mathrm{~h}(P<0.01)$. During this period, $\mathrm{p}$-GluA1 showed the highest level at $10 \mathrm{~min}$ after training. After $1 \mathrm{~h}$, p-GluA 1 expression subsided and did not show any difference from that of the naive group. Each bar in $A$ and $B$ represents $n=12$ pup olfactory bulbs. (B) Total GluA1 expression after training. Western blots revealed no differences between levels of GluA1 expression in the odor plus $2 \mathrm{mg} / \mathrm{kg}$ isoproterenol group and those of naive pups at any time point observed after training. Ratios were relative to actin, which was used as the loading control. Representative blots are shown below the quantitative graphs at the various time points. Each bar represents $N$ values of four or five pups. A microsomal rat brain prep (Upstate) was used as a positive control (+ve) and showed the pGluA1/GluA1 expression at $\sim 106 \mathrm{kDa}$. The actin label was observed around $43 \mathrm{kDa}$. 
of GluA1 subunits was specifically associated with odor preference learning conditions, the 10-min time point was re-examined together with appropriate control conditions.

\section{Pairing modulation of GluAl phosphorylation}

A one-way repeated ANOVA revealed a significant effect of training condition on p-GluA1 level $\left(F_{(3,33)}=5.491, \quad P<0.01\right)$ (Fig. 2A). The olfactory bulbs of pups that were trained to learn (odor $+2 \mathrm{mg} / \mathrm{kg}$ isoproterenol) showed increased levels of p-GluA1 10 min after training (mean \pm SEM $=1.169 \pm 0.1522$ ), compared to those of naive pups (mean $\pm \mathrm{SEM}=0.8281 \pm$ $0.07676, P<0.05$ ) or $2 \mathrm{mg} / \mathrm{kg}$ isoproterenol only pups (mean \pm SEM $=0.8375 \pm 0.1213, P<0.01$ ), respectively. Expression of p-GluA1 in the olfactory bulbs of pups exposed to odor only showed an intermediate level (mean \pm SEM $=1.055 \pm 0.1050$ ), which was not significantly lower than those of the conditioned group or significantly higher than those of the other nonconditioned groups.

Expression of total GluA1 subunits in the olfactory bulbs of both the conditioned and nonconditioned pups did not show any differences among groups in this experiment, as in the previous experiment with naive controls (Fig. 2B).

One day after training, littermates of each group were tested for odor preference. Only the conditioned pups showed significant peppermint preference (mean \pm SEM $=75.6 \% \pm 4.0$ ), compared with nonconditioned pups: naive (mean $\pm \mathrm{SEM}=$ $29.1 \% \pm 5.5, P<0.001$ ), odor only (mean \pm SEM $=41.6 \% \pm 2.2$,
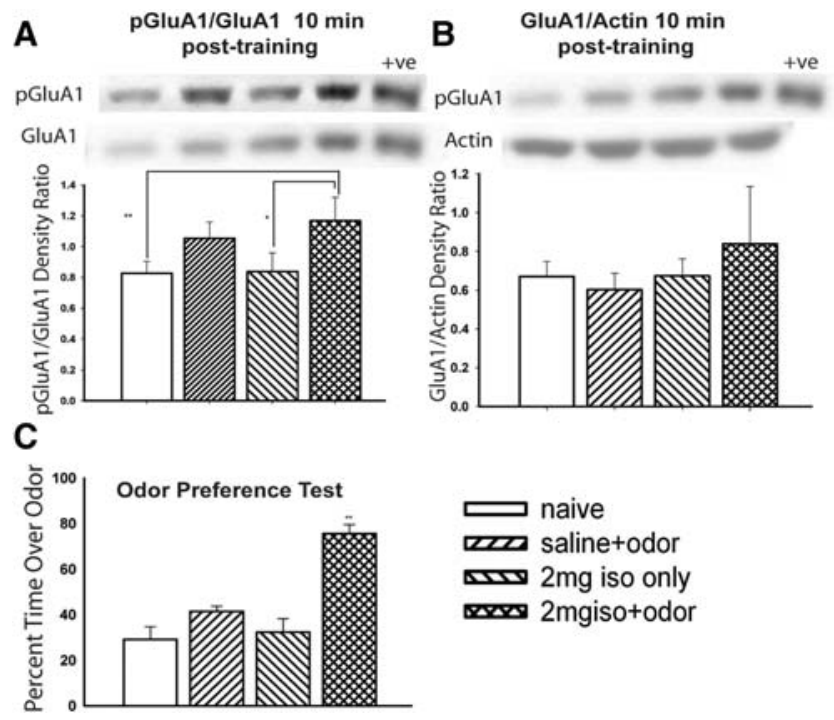

Figure 2. (A) Phospho-GluA1 subunit expression 10 min after training observed by Western blots. The olfactory bulbs of pups that were trained to learn (odor $+2 \mathrm{mg} / \mathrm{kg}$ isoproterenol) showed increased levels of $p$-GluA1 10 min after training, compared to naive pups $(P<$ $0.05)$ or $2 \mathrm{mg} / \mathrm{kg}$ isoproterenol only pups $(P<0.01)$, respectively. Meanwhile, expression of p-GluA1 in pups trained by odor alone showed an intermediate level and was not significantly either lower than that of the conditioned group or higher than those of other nonconditioned groups. Top blots show representative Western blots of the respective lanes/conditions. (B) Total GluA1 subunit expression $10 \mathrm{~min}$ after training. There was no difference in the expression of total GluA1 subunit in olfactory bulbs of conditioned pups (odor $+2 \mathrm{mg} / \mathrm{kg}$ isoproterenol) and nonconditioned pups (naive, odor + saline, or $2 \mathrm{mg} / \mathrm{kg}$ isoproterenol only). (C) Exposure of pups to $10 \mathrm{~min}$ of peppermint odor paired with $2 \mathrm{mg} / \mathrm{kg}$ isoproterenol leads to 24-h odor preference. One day after training, only the pups trained by pairing odor and isoproterenol showed significant peppermint preference. $N=7$ pups per training group.
$P<0.001$ ), and $2 \mathrm{mg} / \mathrm{kg}$ isoproterenol only (mean $\pm \mathrm{SEM}=$ $32.4 \% \pm 5.8, P<0.001)$ pups. Treatment effect $F_{(3,24)}=21.35$, $P<0.0001$ (Fig. 2C).

These data suggest that $\mathrm{S} 845$ phosphorylation of the GluA1 subunit of the AMPA receptor is specific to the association of CS and US in odor preference training. In particular, the failure to see an effect of isoproterenol alone supports the hypothesis that it is the association of odor and reward (isoproterenol) that modifies this receptor. The intermediate levels of phosphorylation in the novel odor only condition may relate to receptor changes associated with odor habituation. The lack of a significant difference in the odor only condition from the other nonlearning condition is consistent with the hypothesis that these changes are insufficient to drive odor preference, as also seen in the behavioral test data. The lack of any difference in total receptors replicates the first experiment, as do the phosphorylation results. The failure of total GluA1 subunits to increase in the initial minutes is not surprising given that an increase in receptor production would require protein synthesis. Nonetheless increases in GluA1 levels over hours could have occurred, but did not. The ensemble of data reveals a learning specific increase in GluA1 phosphorylation peaking $10 \mathrm{~min}$ after a 10-min training trial with no change in the level of total GluA1 subunits up to $24 \mathrm{~h}$ after training.

The failure to see any change in total GluA1 subunits over time suggests additional production of GluA1 subunits is not required to support odor preference memory at $24 \mathrm{~h}$. However, the AMPA receptor insertion hypothesis is not directly tested by these data as an increase in membrane-inserted receptors, taken from the intracellular pool, is the specific change predicted by the hypothesis that AMPA receptor insertion supports memory. Such a redistribution of GluA1 subunits need not be reflected in an overall change in GluA1 levels.

\section{Synaptoneurosome localization of GluAl subunits}

Synaptoneurosome preparations permit the selective examination of membrane-associated GluA1 subunits. Electron microscopic (EM) images from the both fresh and frozen synaptoneurosome extractions were in accord with those of Hollingsworth et al. (1985) and Johnson et al. (1997) in showing vesicular clusters inside synaptosomes (presynaptic components) and attached electron dense neurosomal membrane (post-synaptic). There were no differences between EM profiles following synaptoneurosome extraction in fresh vs. frozen olfactory bulbs. The latter (Fig. 3 as an example) was used to permit collection of the necessary numbers of animals in each training condition.

GluA1 distribution levels in synaptoneurosomes differed significantly across training conditions $\left(F_{(3,21)}=6.988, P<0.01\right)$ $24 \mathrm{~h}$ following training. The synaptoneurosomal GluA1 subunits in the conditioned group (odor $+2 \mathrm{mg} / \mathrm{kg}$ isoproterenol, mean \pm $\mathrm{SEM}=1.545 \pm 0.103$ ) were significantly higher than in the naive group (mean $\pm \mathrm{SEM}=1.248 \pm 0.119, P<0.05$ ) and the odor + saline group (mean $\pm \mathrm{SEM}=1.185 \pm 0.136, P<0.01$ ). However, the $2 \mathrm{mg} / \mathrm{kg}$ isoproterenol only group (mean $\pm \mathrm{SEM}=1.586 \pm$ 0.195 ) also had increased synaptoneurosomal GluA1 subunits, compared to the naive group $(P<0.05)$ and the odor only group $(P<0.01)$, and was not significantly different from the odor and $2 \mathrm{mg} / \mathrm{kg}$ isoproterenol pairing group (Fig. $4 \mathrm{~A}$ ).

Odor preference tests showed significant differences among pups from each treatment group $\left(F_{(3,28)}=26.622, P<0.0001\right)$ (Fig. 4B). Only pups in the odor $+2 \mathrm{mg} / \mathrm{kg}$ isoproterenol group exhibited a significant odor preference (mean \pm SEM $=77.5 \% \pm$ 5.5 ), compared with those in the naive (mean \pm SEM $=26.6 \% \pm$ $6.0, P<0.001$ ), odor plus saline (mean \pm SEM $=21.4 \% \pm 5.2$, $P<0.001$ ), or $2 \mathrm{mg} / \mathrm{kg}$ isoproterenol only group (mean $\pm \mathrm{SEM}=$ $22.9 \% \pm 4.0, P<0.001)$. 


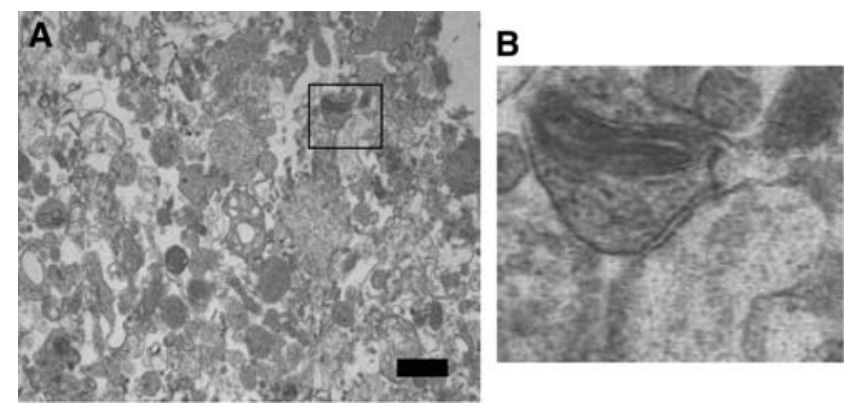

Figure 3. Electron micrographs of synaptoneurosomes isolated from fresh olfactory bulbs of 6-d-old rat pups $(A)$ A large field view of synaptoneurosomes $(10,000 \times)$. The square indicates a complete synaptoneurosome. (B) A close-up view of the synaptoneurosome in the square in $A$, which includes a presynaptic terminal full of synaptic vesicles and a postsynaptic membrane containing post-synaptic densities. Bar in A: $500 \mathrm{~nm}$.

The pattern of GluA1 expression in the synaptoneurosomes supports the AMPA insertion hypothesis, although, there were no overall differences in total GluA1 levels in the olfactory bulb, there were more GluA1 subunits, as predicted, in extrasynaptic and synaptic membranes at $24 \mathrm{~h}$ after training than in nontraining naive or odor only subgroups, which had not acquired an odor preference memory. The finding that the US alone was sufficient to increase membrane insertion of GluA1-containing AMPA receptors is consistent with the observation that NE acting through $\beta$-adrenergic receptors increases extrasynaptic insertion of GluA1 subunits in the hippocampus (Hu et al. 2007). Activation of $\beta$-adrenoceptors by $2 \mathrm{mg} / \mathrm{kg}$ isoproterenol does elevate cAMP, as we have reported, but the pattern differs from that seen with pairing (Cui et al. 2007). Normally, odor conditioning increases cAMP at the end of training, but a return to baseline is seen $5 \mathrm{~min}$ later. With the US ( $2 \mathrm{mg} / \mathrm{kg}$ isoproterenol alone) the return to baseline at $5 \mathrm{~min}$ is not seen. It appears that PKA substrates are phosphorylated with a different time course under the US alone conditions. Other work suggests the initial extrasynaptic insertion of AMPA receptors is triggered by PKA activation, but that the final lateral movements targeting AMPA receptors to synapses and mediating their stabilization at selective synapses is mediated by synaptically driven processes, such as CaMKII activation (Oh et al. 2006). In the present experiments, both extrasynaptic and synaptic membrane insertions would be induced by conditioning. We have recently found an essential role for CaMKII in neonate odor preference learning, suggesting that this system may also merit examination (de Jong et al. 2008).

To assess whether the targeting of the increase in membrane GluA1 subunits was selective to the glomerular region containing olfactory nerve inputs and mitral cell dendrites where GluA1 subunits are normally densest (Petralia and Wenthold 1992), and which is predicted to be the initial site of memory formation in our olfactory bulb learning model (Yuan et al. 2003), we carried out immunohistochemical experiments using the same antibody to GluA1 used in the synaptoneurosomal experiments. We purposely chose a dilution of the GluA1 antibody (1:2000) that resulted in a relatively light label in order to prevent saturation of label that might otherwise obscure differences in conditions with higher concentrations.

There were no differences in GluA1 staining patterns at 10 min after training (Fig. 5A), when phosphorylation of GluA1 is at a maximum. Consistent with the insertion hypothesis, there was a significantly greater density of GluA1-containing AMPA receptors $3 \mathrm{~h}$ (Fig. 5B) and $24 \mathrm{~h}$ (Fig. 5C) after training in the glomerular region of pups that were in the learning condition than of pups that were in any of the three control conditions (naive, odor only, US only). Specifically, pups that were trained to learn (odor plus $2 \mathrm{mg} / \mathrm{kg}$ isoproterenol) showed a total GluA1 expression at $3 \mathrm{~h}$ post-training in the glomerular layer (mean $\pm \mathrm{SEM}=$ $0.1305 \pm 0.011)$ significantly higher $\left(F_{(3,20)}=8.4, \quad P<0.001\right)$ (Fig. 5B) than that of nonconditioned pups, which were in the naive (mean $\pm \mathrm{SEM}=0.07283 \pm 0.005, \quad P<0.01$ ), odor plus saline (mean $\pm \mathrm{SEM}=0.07717 \pm 0.010, P<0.01$ ), or $2 \mathrm{mg} / \mathrm{kg}$ isoproterenol only groups (mean $\pm \mathrm{SEM}=0.08333 \pm 0.009, P<$ 0.01). The total GluA1 expression $24 \mathrm{~h}$ after training in the glomerular layer of olfactory bulbs from pups that were trained to learn (odor plus $2 \mathrm{mg} / \mathrm{kg}$ isoproterenol) showed a similar pattern to that seen at $3 \mathrm{~h}$. In particular, significantly higher levels (mean $\pm \mathrm{SEM}=0.168 \pm 0.004, F_{(3,12)}=11.771, P<0.001$ ) (Fig. 5C) were observed in the olfactory bulbs of paired/learning pups compared with those of pups under nonlearning conditions which included naive (mean $\pm \mathrm{SEM}=0.1115 \pm 0.008, P<0.001$ ), odor plus saline (mean $\pm \mathrm{SEM}=0.123 \pm 0.009, P<0.01$ ), or $2 \mathrm{mg} / \mathrm{kg}$ isoproterenol only (mean $\pm \mathrm{SEM}=0.1263 \pm 0.007, P<$ 0.01). Unlike the synaptoneurosomal pattern, GluA1 staining after $2 \mathrm{mg} / \mathrm{kg}$ isoproterenol alone was not significantly denser in the glomeruli.

It is not known whether the earlier synaptoneurosome results with the isoproterenol US alone reflect a nontargeted increase in membrane-associated GluA1 subunits that is not evident when viewed over a large area anatomically with immunohistochemical staining or whether the orientation of the extrasynaptic subunits following isoproterenol alone is such that they are not available to the antibody in this condition. However, immunohistochemistry reveals that it is only in the pairing condition that GluA1 density is increased in the synaptic regions of the bulb predicted to be associated with memory at the time behavioral memory is being expressed. The overall GluA1 staining pattern resembled that previously reported for PND 6 mice (Hamilton and Coppola 2003).

These results suggest receptor redistribution has occurred by $3 \mathrm{~h}$ and could support the behavioral memory seen in littermates at the 3 -h post-training time point. Thus, both short-term $(3 \mathrm{~h})$

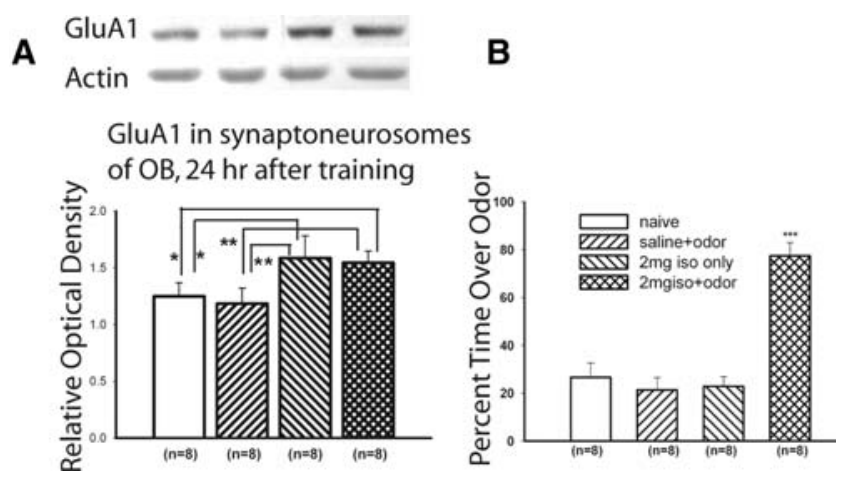

Figure 4. (A) GluA1 expressions in synaptoneurosomes of olfactory bulb using Western blots $24 \mathrm{~h}$ after training. Synaptoneurosomal GluA1 subunits in olfactory bulbs of the conditioned group (odor $+2 \mathrm{mg} / \mathrm{kg}$ isoproterenol) were significantly higher than those of the naive group $(P<$ $0.05)$ and the odor + saline group $(P<0.01)$. Meanwhile, the $2 \mathrm{mg} / \mathrm{kg}$ isoproterenol only group had increased synaptoneurosomal GluA1 as well, compared to the naive group $(P<0.05)$ and the odor only group $(P<0.01)$, and was not different from the odor and $2 \mathrm{mg} / \mathrm{kg}$ isoproterenol pairing group. Representative Western blots are shown above the graphs. Abbreviation: OB (olfactory bulb). (B) Littermates of pups analyzed for olfactory bulb Western blots were analyzed for odor preference $24 \mathrm{~h}$ after training on PND 6 . Only the paired (odor $+2 \mathrm{mg} / \mathrm{kg}$ Iso) group showed significant preference for the conditioned odor. ${ }^{* * *} P<$ 0.001 . 

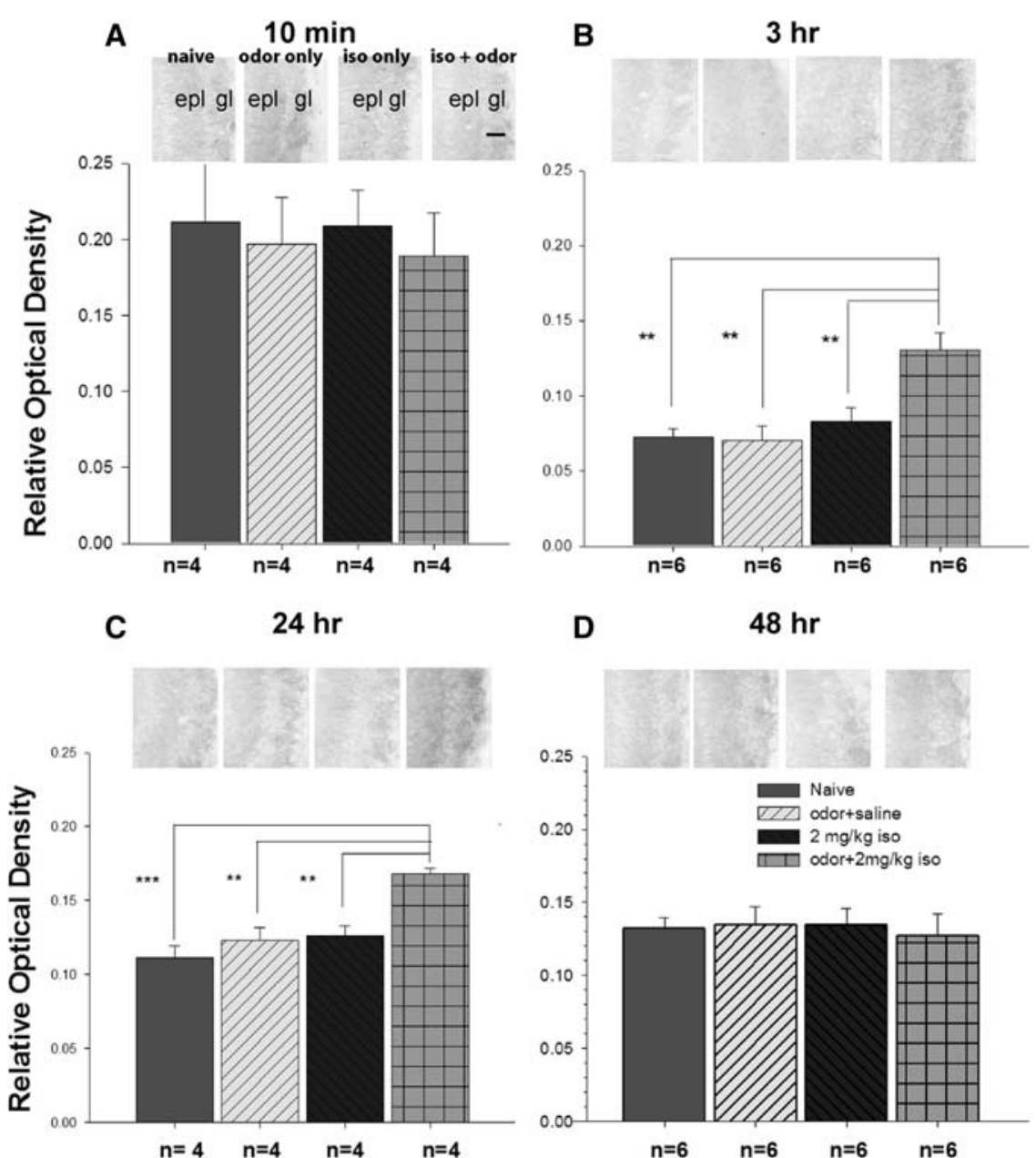

D

$48 \mathrm{hr}$

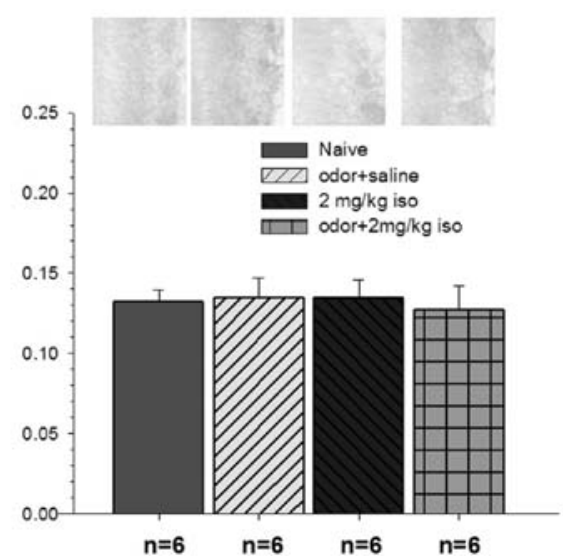

Figure 5. Immunohistochemical expression of GluA1 in the glomerular layer of the olfactory bulbs at various time points after training. (A) GluA1 expression was not affected by training condition $10 \mathrm{~min}$ after training. Compared to other time points, the GluA1 expression appeared darker overall. However, this was likely due to the processing of slides for this time group. (B) Expression of total GluA1 was significantly increased in the glomerular layer $3 \mathrm{~h}$ after training (odor $+2 \mathrm{mg} / \mathrm{kg}$ isoproterenol) compared to the nonlearning groups (naive, odor only, or isoproterenol only). (C) Similar significant differences in GluA1 expression were also observed $24 \mathrm{~h}$ after training. (D) By $48 \mathrm{~h}$ after training, GluA1 expression was not significantly different between training groups. Above the graphs: Representative micrographs show GluA1 expression in sections of olfactory bulbs in each training group. The staining was made purposely light in order to avoid ceiling effects typically found with using too high a concentration of primary antibody. Abbreviations: iso, isoproterenol; epl, external plexiform layer; gl, glomerular layer. Bar in $A$ micrograph: $100 \mu \mathrm{m} .{ }^{* *} P<0.01,{ }^{* * *} P<0.001$.

and long-term $(24 \mathrm{~h})$ memory may be mediated by receptor insertion.

Pups do not show odor preference memory at $48 \mathrm{~h}$ after a single odor training trial so we examined GluA1 staining at $48 \mathrm{~h}$. There were no differences in GluA1 staining density among training or control conditions (Fig. 5D). This is, again, consistent with the hypothesis that GluA1 membrane insertion mediates memory. When memory is not seen, increased selective membrane targeting of GluA1 is no longer evident.

To directly investigate a causal role of GluA1-containing AMPA receptor insertion in odor preference memory, an interference peptide derived from the GluA1 carboxyl tail (Tat-GluA1 $1_{\mathrm{CT}}$ ) (Yu et al. 2008) was locally infused into the olfactory bulb $50 \mathrm{~min}$ before training. The GluA1 $1_{\text {Cт }}$ peptide blocks expression of LTP at thalamo-amygdala synapses, a form of synaptic plasticity dependent on GluA1-dependent AMPA receptor insertion (Yu et al.
2008). One-way ANOVA showed significant differences between the various training groups for 24-h odor preference memory $\quad\left(F_{(2,11)}=17.945, \quad P<0.001\right)$. Post hoc analysis (Student-NewmanKeuls) showed a significant difference between the learning control group ( $2 \mathrm{mg} / \mathrm{kg}$ Iso + odor) vs. the nonlearning control group or the experimental group (Fig. 6). Thus, infusion of the peptide blocked 24-h odor preference memory, in keeping with our earlier evidence showing increased GluA1 expression $24 \mathrm{~h}$ after training (Figs. 4, 5).

\section{Discussion}

\section{Time course of GluAl} phosphorylation following odor preference training

Immediately following odor preference training GluA1 phosphorylation is increased, with a peak occurring $10 \mathrm{~min}$ after training, and a significant increase present at $1 \mathrm{~h}$, but not at $1.5 \mathrm{~h}$. The phosphorylation peak at $10 \mathrm{~min}$ is consistent with peak PKA-mediated phosphorylation of CREB, which occurs following a novel odor CS paired with a stroking US (McLean et al. 1999) or with a $2 \mathrm{mg} / \mathrm{kg}$ isoproterenol US (Yuan et al. 2000), but not to either US alone. NMDA receptors also exhibit peak PKA-mediated phosphorylation at $10 \mathrm{~min}$ after training when $2 \mathrm{mg} / \mathrm{kg}$ isoproterenol is paired as a US (see Supplement 1). Synapsin, a presynaptic substrate for PKA (Hosaka et al. 1999; Angers et al. 2002), does not show a significant phosphorylation change between training groups in this paradigm (see Supplement 2).

Although cAMP is elevated by odor plus $2 \mathrm{mg} / \mathrm{kg}$ isoproterenol and by $2 \mathrm{mg} / \mathrm{kg}$ isoproterenol alone, only the CS + US pairing produces a phasic increase in cAMP, which peaks at the end of the training and returns to basal levels 5 min later. The US alone produces a tonic elevation at the end of training and 5 min later (Cui et al. 2007). A higher isoproterenol dose $(6 \mathrm{mg} / \mathrm{kg})$ that does not produce learning produces a prolonged rising elevation of cAMP. The naturalistic US, stroking, like $2 \mathrm{mg} / \mathrm{kg}$ isoproterenol, produces a phasic peak in cAMP at the end of odor pairing that returns to basal levels 5 min later. Stroking alone also produces a phasic cAMP increase but it is temporally delayed with respect to the 10-min training period (Cui et al. 2007). The phasic "burst-like" increase in cAMP at the end of the 10-min odor exposure period is a unique cAMP CS + US signature associated with PKA phosphorylation of multiple substrates, including GluA1 as seen here. The present result is consistent with a role for covalent receptor modification in shortterm memory. A functional increase in the peak open time of the AMPA receptor (Banke et al. 2000) mediated by the GluA1 phosphorylation could support odor preference memory up to $1.5 \mathrm{~h}$ after training. A significant increase in olfactory nerve field EPSP 


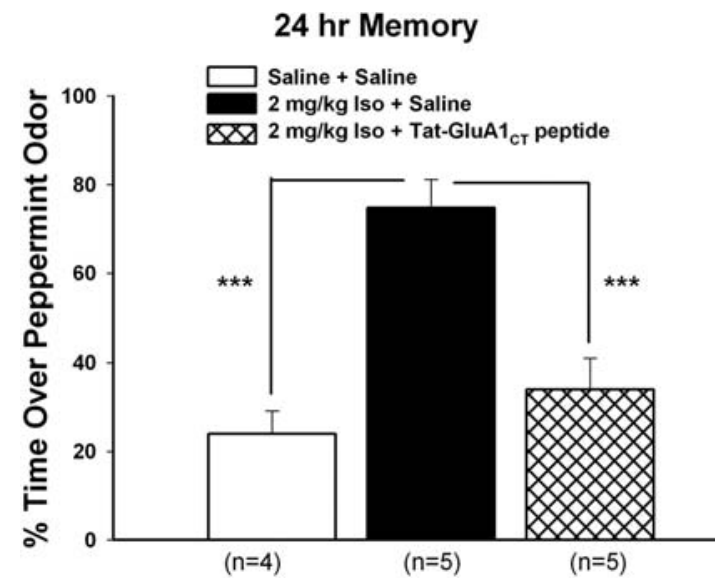

Figure 6. Odor preference test $24 \mathrm{~h}$ following olfactory bulb infusion of the Tat-GluA1 carboxyl tail (Tat-GluA1 ${ }_{\mathrm{CT}}$ ) interference peptide $50 \mathrm{~min}$ before training. Post hoc analysis (Student-Newman-Keuls) showed that the peptide significantly interfered with odor preference memory suggesting a causative role of the GluA1-dependent AMPA receptor insertion in memory. ${ }^{* * *} P<0.001$.

slope following the pairing of olfactory nerve stimulation with $2 \mathrm{mg} / \mathrm{kg}$ isoproterenol has been described (Yuan et al. 2000).

\section{Time course of the increase in membrane-associated GluAl} following odor preference training

The synaptoneurosome preparation reveals a selective increase in membrane-associated GluA1-containing AMPA receptors $24 \mathrm{~h}$ after training when robust odor preference memory is expressed. An increase in GluA1 staining density is seen in the glomeruli at the same time point consistent with an increase in GluA1 subunits in synapse-associated membranes at the time of memory expression. The increased glomerular GluA1 staining density was also present $3 \mathrm{~h}$ after training. In addition, the present finding that a blockade of GluA1-dependent insertion disrupts long-term odor preference memory (Fig. 6) is consistent with a role for GluA1 insertion establishing the odor preference memory. Previous work has shown the involvement of AMPA receptor insertion for LTP in the lateral amygdala (Yu et al. 2008) and hypotheses put forth by others concerning the GluA1 receptor (Shi et al. 2001; Malinow and Malenka 2002).

Two fear conditioning models have reported an increase in GluA1 membrane-associated subunits $24 \mathrm{~h}$ after conditioning. In a cued fear conditioning study synaptoneurosomes from the amygdala showed higher GluA1 levels from 2 to $24 \mathrm{~h}$ after fear conditioning, but not earlier (Yeh et al. 2006). Increases were not seen in unpaired controls or in the hippocampus or the cortex. In a contextual fear conditioning study, GFP-GluA1 subunits were significantly elevated in hippocampal CA1 pyramidal layer membranes from 2 to $24 \mathrm{~h}$ after conditioning, but not earlier (Matsuo et al. 2008). Control conditions also showed an elevation in membrane-associated GluA1 subunits, however a detailed analysis at $24 \mathrm{~h}$ revealed that the paired group had a selective increase in GluA1 subunits in mushroom spines. This pattern was not seen in the control groups supporting a synaptic tagging hypothesis. The GluA1 increase was not apparent $72 \mathrm{~h}$ after conditioning, although fear behavior was still expressed.

A third study of cued fear conditioning used exogenous GluA1 subunits to assess their participation at synapses as indexed by an ex vivo change in rectification. Increases were seen $3 \mathrm{~h}$ following training (Rumpel et al. 2005). The study also demonstrated that infusion of GluA1 subunits that could not be incorporated prevented learning at $24 \mathrm{~h}$ arguing for a causal role for GluA1 subunit insertion. In contrast to these studies with longer lasting increases in GluA1, a study of inhibitory avoidance found GluA1 increases in synaptoneurosomes peaking at $30 \mathrm{~min}$ and returning to baseline prior to $2 \mathrm{~h}$ (Whitlock et al. 2006). The investigators suggest that the signal was only in a subset of cells and may have been lost in the noise over time.

With the exception of the latter study, the present results in an appetitive model are consistent with the outcomes in aversive learning models in that GluA1 increases are seen within a few hours after conditioning and remain detectable for $24 \mathrm{~h}$. Taken together it appears that membrane insertion of GluA1 subunits could support both short-term and long-term memory in the amygdala, the hippocampus, and the olfactory bulb. The failure to see an increase in GluA1 staining density at $48 \mathrm{~h}$ here was consistent with the loss of odor preference at that time. However, aversive conditioning studies have not demonstrated GluA1 insertion at extended time points when memory is still expressed, suggesting a change in the memory mediating mechanism with time. It will be of interest to use a repeated-trials odor preference model, which induces memory expression over weeks and months to explore longer time points for GluA1 increases in the glomeruli.

The lack of a GluA1 immunohistochemical staining increase 10 min following training is consistent with subunit insertion as a process following peak S845 phosphorylation which occurs 10 min after training. Once initiated, membrane-associated GluA1 increases in this study appear to be maintained in the absence of continued subunit phosphorylation. This is similar to the effects of $\beta$-adrenoceptor activation in the hippocampus in vitro where S845 phosphorylation of the GluA1 subunit peaks at the end of a 10 min NE application, maximally facilitating LTP and the insertion of GluA1 subunits into synapses at this time. S845 phosphorylation declines to baseline 90 min later and LTP facilitation is correspondingly absent (Hu et al. 2007). Potentiation of fear memory $48 \mathrm{~h}$ after exposure to NE during training was interpreted as increased GluA1 insertion during learning mediated by $\mathrm{S} 845$ phosphorylation (Hu et al. 2007). Although not visualized directly in that study, phospho-mutants preventing S845 phosphorylation did not show NE potentiation of 48 -h fear memory.

\section{Discrepancies}

Although the patterns of GluA1 phosphorylation and insertion dovetail compellingly with rat pup learning and memory of odor preference, there are discrepancies from predicted patterns. Isoproterenol alone increased GluA1 levels in synaptoneurosomes $24 \mathrm{~h}$ after exposure. This increase in membrane-associated GluA1 levels was not detectable with immunohistochemistry. Increased glomerular GluA1 density was only seen with pairing and not with odor or US alone. This suggests a possible diffuse increase in extrasynaptic receptors initiated by the US as suggested in the two-stage hypothesis (Oh et al. 2006), but no translocation and stabilization at synapses. If such an extrasynaptic increase is occurring, one might predict facilitation of conditioning at $24 \mathrm{~h}$ by prior exposure to isoproterenol. This remains to be tested. The failure to see any difference with the antibody used for Western blotting in the immunohistochemical experiments suggests the protein is not configured in the same way in situ as in the membrane-enriched homogenate after isoproterenol alone.

Another unexpected effect was the intermediate increase in the phosphorylation of GluA1 with novel odor exposure alone. It is likely that novel odor has an arousing effect possibly associated with NE release. Nonetheless, there is no increase in synaptoneurosomal GluA1 levels to novel odor and no increase in odor 
preference. An intermediate pCREB increase to odor alone was seen in an earlier study at the same age (McLean et al. 1999). The intermediate phosphorylation level may be associated with odor habituation as suggested by studies linking LTD and S845 phosphorylation of GluA1 (Lee et al. 2010).

Two aversive learning studies have directly examined phosphorylation of GluA1 sites following learning, in those studies learning was associated with phosphorylation on S831, the calmodulin kinase site, rather than the PKA-associated S845 site (Whitlock et al. 2006; Shukla et al. 2007). The occurrence of S845 phosphorylation in mammalian appetitive learning here may be related to separate biogenic amine substrates for aversive vs. appetitive learning as described for insects (Schwaerzel et al. 2003; Vergoz et al. 2007; Mizunami et al. 2009). However, priming of aversive conditioning by norepinephrine appears to increase S845 phorphorylation to a greater extent than that of S831 and, unexpectedly, a $\beta$-adrenergic blocker prevented phosphorylation of both substrates in an in vitro LTP priming experiment. Phosphomutant studies suggest that both sites have a role in LTP, whereas LTD may have an exclusive dependence on S845 (Lee et al. 2010). As already mentioned blocking phosphorylation of S845 prevents priming of fear conditioning, consistent with a role for S845 phosphorylation in promoting aversive learning.

\section{Conclusions}

The present study provides evidence for the hypothesis that membrane-associated glomerular AMPA receptor increases support 3- and 24-h memory following a single odor preference training session. This result suggests increased GluA1 membrane insertion could contribute to both short-term and long-term odor preference memory. Membrane insertion is temporally preceded by GluA1 phosphorylation as predicted from mechanistic studies. As GluA1 phosphorylation at S845 increases the probability of the open state of the AMPA receptor, this change could provide initial support for short term memory. Loss of the GluA1 redistribution pattern at $48 \mathrm{~h}$ is congruent with failure to observe an odor preference in rat pups at $48 \mathrm{~h}$.

\section{Materials and Methods}

\section{Experimental design}

In an initial series of experiments total GluA1 protein and GluA1 phosphorylation on the PKA-targeted serine 845 site were characterized in naive and trained rat pups at a series of times after training. Following identification of the temporal peak of GluA1 phosphorylation in trained pups, a set of additional pups with odor only or the US only were run against the naive and training conditions to confirm pairing-specific mediation. Littermates exposed to the same training and control conditions were tested behaviorally $24 \mathrm{~h}$ later.

In a second set of experiments the level of GluA1 subunits in olfactory bulb synaptoneurosomes was characterized at $24 \mathrm{~h}$ following training. Subsequent immunohistochemical experiments visualized the glomerular distribution and level of GluA1 subunits at $10 \mathrm{~min}, 3,24$, and $48 \mathrm{~h}$ after training.

Animals
Sprague-Dawley rat pups of both sexes were used in the studies.
Litters were culled to 12 pups per litter on post-natal day (PND)
1 (the day of birth is considered PND 0). The dams were main-
tained under a 12 -h light-dark cycle at $22^{\circ} \mathrm{C}$ in polycarbonate
cages containing hardwood chips at the Health Sciences Centre
of Memorial University of Newfoundland animal care facility.
Food and water were accessible ad libitum. All experimental pro-
cedures were approved by the Memorial University Institutional
Animal Care Committee, and conformed to the standards set by the Canadian Council on Animal Care.

A maximum of one male and female pup from the same litter was used for each training group. All training sessions were done in an experimental room where the temperature was kept constant at $28^{\circ} \mathrm{C}$. This allowed pups to maintain body temperature in the absence of the dam.

\section{Pup training}

On PND 6, $2 \mathrm{mg} / \mathrm{kg}$ isoproterenol ( $\beta$-adrenoceptor agonist, Sigma Chemical) was injected subcutaneously 40 min prior to odor preference training. Thirty min following injection, the pups were removed from the dam and placed in a clean holding cage. Ten min later, they were placed on peppermint-scented bedding $(0.3 \mathrm{~mL}$ peppermint extract in $500 \mathrm{~mL}$ fresh bedding) for 10 min. Pups were killed by decapitation and olfactory bulbs were collected at designated time points. Littermates were tested for odor preference memory $24 \mathrm{~h}$ later.

\section{Pup testing}

The PND 7 choice test was carried out in a stainless steel test box $(30 \times 20 \times 18 \mathrm{~cm})$ with a polypropylene mesh screen inside placed on two trays, which were separated by a $2-\mathrm{cm}$ neutral zone. One tray contained fresh normal bedding; the other contained peppermint-scented bedding. Each pup was removed from the dam and placed in the neutral zone of the test box, when testing started. The amount of time the pup spent on either peppermint-scented bedding or normal bedding was recorded during each of five 1-min trials. Time recording was started when a pup moved its snout and one paw into either bedding side. The percentage of time the pup spent over the peppermintscented bedding during the five trials was calculated as: time over peppermint-scented bedding/time over both peppermintscented and normal bedding.

\section{Western blots}

\section{GluAl phosphorylation experiments in whole bulb}

To establish levels of phosphorylated GluA1 and total GluA1 following training, 53 Sprague-Dawley rat pups from five litters were used. Eleven training groups were included: one naive group, and ten odor $+2 \mathrm{mg} / \mathrm{kg}$ isoproterenol groups sacrificed at different time points: the end of training, $5,10,20,30 \mathrm{~min}, 1,1.5,2$, 3 , and $24 \mathrm{~h}$ after training.

In the follow-up experiment, pairing effects were examined 10 min after training, the peak GluA1 serine 845 phosphorylation time point observed in the preceding experiment. Forty-eight rat pups from six litters were used for Western blot measurements. Four groups were included: naive, odor plus saline (odor only), $2 \mathrm{mg} / \mathrm{kg}$ isoproterenol only, and odor plus $2 \mathrm{mg} / \mathrm{kg}$ isoproterenol. In addition, 28 rat pups including littermates from the original six litters and additional pups from a seventh litter distributed over the same four training groups were tested for odor preference on PND 7.

\section{Sample collection and protein determination}

At the designated time point, pups in the relevant groups were killed by decapitation. Both olfactory bulbs of each pup were quickly removed from the skull and flash frozen on dry ice. All samples were subsequently stored at $-80^{\circ} \mathrm{C}$ in microcentrifuge tubes until use. Protein of the olfactory bulbs collected from the same litter was determined in the same plate and analyzed in the same gel and same membrane when performing Western blots. Each pair of olfactory bulbs was ground by a homogenizer in $100 \mu \mathrm{L}$ ice-cold lyses buffer containing $0.1 \%$ SDS, $10 \% \mathrm{NP}-40$, $20 \mathrm{mM}$ Tris, $10 \%$ glycine, and $1.37 \mathrm{mM}$ sodium chloride with $2 \mu \mathrm{g} / \mathrm{mL}$ leupeptin, $2 \mathrm{mM}$ PMSF, $19 \mu \mathrm{g} / \mathrm{mL}$ aprotinin, $1 \mathrm{mM}$ sodium vanadate, and $2.1 \mathrm{mg} / \mathrm{mL}$ sodium fluoride. The homogenate was rotated for $30 \mathrm{~min}$ and then centrifuged at 13,500 rpm for $15 \mathrm{~min}$ at $4^{\circ} \mathrm{C}$. The clear lysate supernatant containing the 
proteins of interest was retained and the pellet was discarded. The protein concentration in the supernatant was determined by a BCA protein assay kit (Pierce).

\section{Western blot preparation}

All sample lysates were prepared using $4 \mu \mathrm{L}$ of $5 \mathrm{X}$ sample buffer (0.3 M Tris- $\mathrm{HCl}, 10 \%$ SDS, $50 \%$ glycerol, $0.05 \%$ bromophenol blue, and $0.5 \mathrm{M}$ dithiothreitol added just prior to use), volumes of lysate that contained $50 \mu \mathrm{g}$ of protein and sufficient $\mathrm{dH}_{2} \mathrm{O}$ to bring the total volume to $20 \mu \mathrm{L}$. Sample solutions were boiled for $5 \mathrm{~min}$ and placed on ice until use. The positive control $(20 \mu \mathrm{L})$ was prepared by adding $4 \mu \mathrm{L}$ of $5 \mathrm{X}$ sample buffer and $12 \mu \mathrm{L} \mathrm{d} \cdot \mathrm{H}_{2} \mathrm{O}$ to $4 \mu \mathrm{L}$ of rat brain microsomal preparation (Upstate); then this was incubated at $37^{\circ} \mathrm{C}$ for $30 \mathrm{~min}$. For each $7.5 \%$ SDS-PAGE gel, one positive control, one color-coded molecular weight standard (10 $\mu \mathrm{L}$, Invitrogen) and sample solutions were loaded into separate lanes.

After loading the samples in lanes, the gel apparatus was attached to a Bio-Rad power supply set at $60 \mathrm{~mA}$ for $10 \mathrm{~min}$; then the current was reset at $30 \mathrm{~mA}$ until the blue line of the sample buffer ran out of the gel (usually $\sim 90 \mathrm{~min}$ ). The gel-running buffer contained $25 \mathrm{mM}$ Tris, $250 \mathrm{mM}$ glycine, and $3.5 \mathrm{mM}$ SDS at $\mathrm{pH}$ 8.8. Proteins in the gel were transferred for $1 \mathrm{~h}$ to a nitrocellulose membrane (Amersham) in transfer buffer $(25 \mathrm{mM}$ Tris, $192 \mathrm{mM}$ glycine, 20\% methanol, pH 8.3) using a transfer apparatus set at $350 \mathrm{~mA}$.

Following transfer, the nitrocellulose membranes were rinsed $2 \times 5 \mathrm{~min}$ in TBST (Tris-Buffered Saline Tween-20, $20 \mathrm{mM}$ Tris, $137 \mathrm{mM}$ sodium chloride, $0.1 \%$ Tween 20) and then immersed and rotated in 5\% milk in TBST for $1 \mathrm{~h}$. Following $2 \times$ 5 min rinses in TBST, the blots were incubated in solution containing 3\% milk in TBST overnight with agitation at $4^{\circ} \mathrm{C}$ in one of the following antibodies: pGluA1 (s845, 1:1000, Upstate), GluR (1:4000, Chemicon), or anti-Actin (1:5000, Sigma). Following $5 \times 5$ min washes in TBST on the second day, blots were incubated in goat-anti-rabbit IgG-horseradish peroxidase $(1: 10,000$, Pierce) with $2 \%$ milk in TBST for $1 \mathrm{~h}$. The blots were rinsed $3 \times 10 \mathrm{~min}$ in TBST and visualized by immersing in SuperSignal West Pico Chemiluminescent Substrate (Pierce) for $5 \mathrm{~min}$ and exposed to films (AGFA).

If GluA1 was examined, blots were subsequently rinsed in TBST for $2 \times 10 \mathrm{~min}$; then were immersed in stripping buffer (3.9\% $\beta$-mercaptoethanol, $2 \%$ SDS, $62.5 \mathrm{mM}$ Tris), and agitated for $10 \mathrm{~min}$ at $50^{\circ} \mathrm{C}$. Blots were then rinsed $2 \times 10 \mathrm{~min}$ in TBST and incubated in either anti-GluA1 (1:4000, Chemicon), or anti-Actin (1:5000, Sigma) overnight at $4^{\circ} \mathrm{C}$. The following day, the procedures for incubating in secondary antibody and exposure as mentioned previously were repeated.

\section{Western blots preparations using synaptoneurosomes}

For Western blot experiments of synaptoneurosomes, 32 SpragueDawley rat pups from four litters were used. Four groups were included: naive, odor plus saline (odor only), $2 \mathrm{mg} / \mathrm{kg}$ isoproterenol only, and odor plus $2 \mathrm{mg} / \mathrm{kg}$ isoproterenol. Behavioral testing of the four conditions was carried out at $24 \mathrm{~h}$ on 32 pups from the littermate cohort of synaptoneurosome pups supplemented with pups from another four litters.

Olfactory bulbs (both fresh and frozen) were homogenized in $1.5 \mathrm{~mL}$ ice-cold buffer ProteoExtract containing protease inhibitors according to kit instructions (ProteoExtract7, Calbiochem). Supernatants were passed through two $100-\mu \mathrm{m}$ nylon mesh filters, followed by a $5-\mu \mathrm{m}$ pore filter. The filtrate was then centrifuged at $1000 \mathrm{~g}$ for $10 \mathrm{~min}$. The extracted pellets of synaptoneurosomes were gently resuspended in $20 \mu \mathrm{L}$ boiled $1 \%$ SDS.

Twenty-four Sprague-Dawley rat pups (six males and six females from one litter and six males and six females from another litter) were used to develop synaptoneurosome methodology for fresh and frozen olfactory bulbs.

The supernatant was discarded and pellets were prepared for electron microscopy (EM) examination. Pellets were fixed in Karnovsky fixative, post-fixed in osmium tetroxide, then dehydrated and embedded in TAAB 812 resin. Sections were cut on an ultramicrotome, stained with uranyl acetate and lead citrate, and examined in a Phillips 300 transmission electron microscope.

\section{Image analysis of Western blots}

Images of blots exposed on the film were captured by the Kodak Gel Logic 200 system. Optical density of each band was measured using Kodak MI software, which automatically subtracted the background. Relative OD of p-GluA1 is the outcome of its OD normalized by that of GluA1; relative OD of GluA1 is its OD divided by that of Actin, the loading control.

\section{Immunohistochemical experiments}

In these experiments four groups were included: naive, odor plus saline (odor only), $2 \mathrm{mg} / \mathrm{kg}$ isoproterenol only, and odor plus $2 \mathrm{mg} / \mathrm{kg}$ isoproterenol. Sprague-Dawley rat pups from these groups were perfused as described previously (McLean et al. 1999) either $10 \mathrm{~min}(n=16), 3 \mathrm{~h}(n=24), 24 \mathrm{~h}(n=16)$, or $48 \mathrm{~h}$ $(n=24)$ after training and the brains stored at $4^{\circ} \mathrm{C}$ in $20 \%$ sucrose.

The following day, brains were quick-frozen in dry ice and cut in coronal sections at $30-\mu \mathrm{m}$ thickness using a cryostat set at $-20^{\circ} \mathrm{C}$. Every sixth section was taken.

Immunohistochemical procedures were standard for this laboratory as published previously (McLean et al. 1999; McLean et al. 2001). Briefly, the GluA1 antibody, diluted 1:1000 or 1:2000 (Chemicon) in phosphate buffered saline with $0.2 \%$ Triton $\mathrm{X}-100,0.02 \%$ sodium azide and $5 \%$ normal goat serum, was placed on the sections overnight at $4^{\circ} \mathrm{C}$ in a humidified chamber. The next day sections were incubated in biotinylated secondary (Vectastain) followed by vidin biotin peroxidase complex and developed in $0.05 \%$ DAB with $0.01 \% \mathrm{H}_{2} \mathrm{O}_{2}$ for $5-8 \mathrm{~min}$. Then sections were dehydrated and covered by a cover slip using Permount mounting medium (Fisher Scientific). Olfactory bulb sections from pups in different groups within the same litter had identical times for incubation in the antibodies and development in DAB solutions. The primary antibody was deliberately kept at a relatively high dilution in order to prevent any ceiling effect of protein expression that would have been expressed with higher concentrations.

The GluA1 stain was analyzed by a Bioquant image analysis system (R\&M Biometrics). Sections were coded so the experimenter was blind to the treatment condition. Images of sections were captured by a CCD camera connected with a Leitz microscope using a $4 \times$ objective. Light intensity from the microscope was always set at an OD of 220. The OD of the olfactory nerve layer of each section was considered as the background for that section. Regions of interest (ROI) were circled on the glomerular layer of the olfactory bulb sections on the computer screen. The relative OD of the ROI in the glomerular layer was obtained by the calculation: (OD of background - OD of $\mathrm{ROI}$ )/OD of background. Regions analyzed included dorsolateral, ventrolateral, dorsomedial, and ventromedial quadrants of each section at three levels defined by distance from the rostral pole of the olfactory bulb, rostral $(100-700 \mu \mathrm{m})$, middle $(800-1400 \mu \mathrm{m})$, and caudal $(1500-$ $2000 \mu \mathrm{m})$.

\section{Interference peptide experiment}

On PND 5, pups were anaesthetized and implanted with infusion cannulae into the olfactory bulbs as described previously (Rumsey et al. 2001). On PND 6, 50 min before odor training, pups infused with either the Tat-GluA1 $1_{\mathrm{CT}}$ peptide $(200 \mathrm{ng} / \mu \mathrm{L} ; 1.0 \mu \mathrm{L})$ or vehicle over $1 \mathrm{~min}$. The peptide was derived from a portion of the GluA1 carboxyl tail (830QSINEAIRTSTLPRNSG846) and fused to the transduction domain of the Tat promoter (YGRKKRRQRRR) as previously described (Brebner et al. 2005; Yu et al. 2008; Collingridge et al. 2010). Ten min after the infusion, pups were injected with $2 \mathrm{mg} / \mathrm{kg}$ isoproterenol or saline (s.c.). Pups were then trained as previously described in the Pup Training section and tested $24 \mathrm{~h}$ after training as described in the Pup Testing section. 


\section{Statistical analysis}

A one-way repeated measures ANOVA was used to analyze the time course of p-GluA1 and GluA1 expression in relation to training. In all subsequent experiments four groups were assessed, a training group and three control conditions, and oneway ANOVAs were used to probe differences among these groups on the relevant measures. Post hoc comparisons were performed by the Least Significant Differences test for the time series and using the Student-Newman-Keuls tests for the pairing experiments.

\section{Acknowledgments}

This work was funded by CIHR grant no. MOP 53761. We thank Kate Williams for preparation of electron microscopic material and Josh Mercer and Andrew Reid for undertaking experiments for the Supplemental Material.

\section{References}

Angers A, Fioravante D, Chin J, Cleary LJ, Bean AJ, Byrne JH. 2002. Serotonin stimulates phosphorylation of Aplysia synapsin and alters its subcellular distribution in sensory neurons. J Neurosci 22: 5412 5422 .

Banke TG, Bowie D, Lee H, Huganir RL, Schousboe A, Traynelis SF. 2000. Control of GluR1 AMPA receptor function by cAMP-dependent protein kinase. J Neurosci 20: 89-102.

Brebner K, Wong TP, Liu L, Liu Y, Campsall P, Gray S, Phelps L, Phillips AG, Wang T. 2005. Nucleus accumbens long-term depression and the expression of behavioral sensitization. Science 310: 1340-1343.

Collingridge GL, Peaineu S, Howland JG, Wang YT. 2010. Long-term depression in the CNS. Nat Rev Neurosci 11: 459-473.

Cui W, Smith A, Darby-King A, Harley CW, McLean JH. 2007. A temporal-specific and transient cAMP increase characterizes odorant classical conditioning. Learn Mem 14: 126-133.

de Jong JD, Harley CW, McLean JH. 2008. CaMKII activation modulates associative odor preference learning. Soc Neurosci Abst 38: 688.17.

Hamilton KA, Coppola DM. 2003. Distribution of GluR1 is altered in the olfactory bulb following neonatal naris occlusion. J Neurobiol 54: 326-336.

Hammer M. 1993. An identified neuron mediates the unconditioned stimulus in associative olfactory learning in honeybees. Nature 366: $59-63$.

Hammer M, Menzel R. 1998. Multiple sites of associative odor learning as revealed by local brain microinjections of octopamine in honeybees. Learn Mem 5: 146-156.

Hollingsworth EB, McNeal ET, Burton JL, Williams RJ, Daly JW, Creveling CR. 1985. Biochemical characterization of a filtered synaptoneurosome preparation from guinea pig cerebral cortex: Cyclic adenosine $3^{\prime}: 5^{\prime}$-monophosphate-generating systems, receptors, and enzymes. J Neurosci 5: 2240-2253.

Hosaka M, Hammer RE, Sudhof TC. 1999. A phospho-switch controls the dynamic association of synapsins with synaptic vesicles. Neuron $\mathbf{2 4}$ $377-387$.

Hu H, Real E, Takamiya K, Kang MG, Ledoux J, Huganir RL, Malinow R. 2007. Emotion enhances learning via norepinephrine regulation of AMPA-receptor trafficking. Cell 131: 160-173.

Johnson MW, Chotiner JK, Watson JB. 1997. Isolation and characterization of synaptoneurosomes from single rat hippocampal slices. J Neurosci Methods 77: 151-156

Lee HK, Takamiya K, Han IS, Man H, Kim CH, Rumbaugh G, Yu S, Ding L, He C, Petralia RS, et al. 2003. Phosphorylation of the AMPA receptor GluR1 subunit is required for synaptic plasticity and retention of spatial memory. Cell 112: 631-643.

Lee HK, Takamiya K, He K, Song L, Huganir RL. 2010. Specific roles of AMPA receptor subunit GluR1 (GluA1) phosphorylation sites in regulating synaptic plasticity in the CA1 region of hippocampus. J Neurophysiol 103: $479-489$.

Lynch G, Baudry M. 1984. The biochemistry of memory: A new and specific hypothesis. Science 224: $1057-1063$.

Malinow R, Malenka RC. 2002. AMPA receptor trafficking and synaptic plasticity. Annu Rev Neurosci 25: 103-126.

Matsuo N, Reijmers L, Mayford M. 2008. Spine-type-specific recruitment of newly synthesized AMPA receptors with learning. Science 319: 1104-1107.

McLean JH, Harley CW, Darby-King A, Yuan Q. 1999. pCREB in the neonate rat olfactory bulb is selectively and transiently increased by odor preference-conditioned training. Learn Mem 6: 608-618.
McLean JH, Darby-King A, Bonnell WS. 2001. Neonatal olfactory sensory deprivation decreases BDNF in the olfactory bulb of the rat. Dev Brain Res 128: 17-24.

McLean JH, Darby-King A, Harley CW. 2005. Potentiation and prolongation of long-term odor memory in neonate rats using a phosphodiesterase inhibitor. Neuroscience 135: 329-334.

Mizunami M, Unoki S, Mori Y, Hirashima D, Hatano A, Matsumoto Y. 2009. Roles of octopaminergic and dopaminergic neurons in appetitive and aversive memory recall in an insect. BMC Biol 7: 46. doi: 10.1186/ 1741-7007-7-46.

Oh MC, Derkach VA, Guire ES, Soderling TR. 2006. Extrasynaptic membrane trafficking regulated by GluR1 serine 845 phosphorylation primes AMPA receptors for long-term potentiation. J Biol Chem $\mathbf{2 8 1}$ : $752-758$.

Petralia RS, Wenthold RJ. 1992. Light and electron immunocytochemical localization of AMPA-selective glutamate receptors in the rat brain. J Comp Neurol 318: 329-354.

Rumpel S, Ledoux J, Zador A, Malinow R. 2005. Postsynaptic receptor trafficking underlying a form of associative learning. Science 308: $83-88$.

Rumsey JD, Darby-King A, Harley CW, McLean JH. 2001. Infusion of the metabotropic receptor agonist, DCG-IV, into the main olfactory bulb induces olfactory preference learning in rat pups. Dev Brain Res 128: $177-179$.

Scheiner R, Baumann A, Blenau W. 2006. Aminergic control and modulation of honeybee behaviour. Curr Neuropharmacol 4: 259-276.

Schwaerzel M, Monastirioti M, Scholz H, Friggi-Grelin F, Birman S, Heisenberg M. 2003. Dopamine and octopamine differentiate between aversive and appetitive olfactory memories in Drosophila. J Neurosci 23: $10495-10502$.

Shi S, Hayashi Y, Esteban JA, Malinow R. 2001. Subunit-specific rules governing AMPA receptor trafficking to synapses in hippocampal pyramidal neurons. Cell 105: 331-343.

Shukla K, Kim J, Blundell J, Powell CM. 2007. Learning-induced glutamate receptor phosphorylation resembles that induced by long term potentiation. J Biol Chem 282: 18100-18107.

Sullivan RM, Wilson DA, Leon M. 1989. Norepinephrine and learninginduced plasticity in infant rat olfactory system. J Neurosci 9: 3998-4006.

Sullivan RM, McGaugh JL, Leon M. 1991. Norepinephrine-induced plasticity and one-trial olfactory learning in neonatal rats. Brain Res Dev Brain Res 60: 219-228.

Sullivan RM, Zyzak DR, Skierkowski P, Wilson DA. 1992. The role of olfactory bulb norepinephrine in early olfactory learning. Brain Res Dev Brain Res 70: 279-282.

Sullivan RM, Stackenwalt G, Nasr F, Lemon C, Wilson DA. 2000. Association of an odor with activation of olfactory bulb noradrenergic $\beta$-receptors or locus coeruleus stimulation is sufficient to produce learned approach responses to that odor in neonatal rats. Behav Neurosci 114: $957-962$.

Sun X, Zhao Y, Wolf ME. 2005. Dopamine receptor stimulation modulates AMPA receptor synaptic insertion in prefrontal cortex neurons. I Neurosci 25: 7342-7351.

Unoki S, Matsumoto Y, Mizunami M. 2005. Participation of octopaminergic reward system and dopaminergic punishment system in insect olfactory learning revealed by pharmacological study. Eur J Neurosci 22: 1409-1416.

Vergoz V, Roussel E, Sandoz JC, Giurfa M. 2007. Aversive learning in honeybees revealed by the olfactory conditioning of the sting extension reflex. PLoS One 2: e288. doi: 10.1371/journal.pone. 0000288.

Whitlock JR, Heynen AJ, Shuler MG, Bear MF. 2006. Learning induces long-term potentiation in the hippocampus. Science 313: 1093-1097.

Yeh SH, Mao SC, Lin HC, Gean PW. 2006. Synaptic expression of glutamate receptor after encoding of fear memory in the rat amygdala. $\mathrm{Mol}$ Pharmacol 69: 299-308.

Yu SY, Wu DC, Liu L, Ge Y, Wang YT. 2008. Role of AMPA receptor trafficking in NMDA receptor-dependent synaptic plasticity in the rat lateral amygdala. J Neurochem 106: 889-899.

Yuan Q, Harley CW, Bruce JC, Darby-King A, McLean JH. 2000. Isoproterenol increases CREB phosphorylation and olfactory nerve-evoked potentials in normal and 5-HT-depleted olfactory bulbs in rat pups only at doses that produce odor preference learning. Learn Mem 7: 413-421.

Yuan Q, Harley CW, McLean JH. 2003. Mitral cell $\beta 1$ and 5-HT2A receptor colocalization and cAMP coregulation: A new model of norepinephrine-induced learning in the olfactory bulb. Learn Mem 10: $5-15$

Received August 18, 2010; accepted in revised form February 10, 2011. 


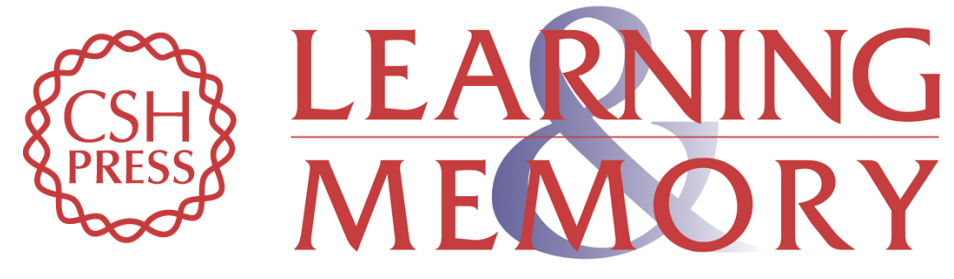

Odor preference learning and memory modify GluA1 phosphorylation and GluA1 distribution in the neonate rat olfactory bulb: Testing the AMPA receptor hypothesis in an appetitive learning model

Wen Cui, Andrea Darby-King, Matthew T. Grimes, et al.

Learn. Mem. 2011, 18:

Access the most recent version at doi:10.1101//m.1987711

Supplemental http://learnmem.cshlp.org/content/suppl/2011/04/11/18.5.283.DC1

Material

References This article cites 42 articles, 19 of which can be accessed free at:

http://learnmem.cshlp.org/content/18/5/283.full.html\#ref-list-1

License

Email Alerting

Receive free email alerts when new articles cite this article - sign up in the box at the Service top right corner of the article or click here. 